\title{
José Carlos Mariátegui y el futurismo italiano: una perspectiva latinoamericana*
}

\author{
Lucía Rey \\ U. de Chile \\ luciareyo@gmail.com
}

\begin{abstract}
Resumen
José Carlos Mariátegui fue un intelectual político y activista cultural peruano que se ocupó de comprender y promover el arte de vanguardia desde la perspectiva de un marxismo latinoamericano. En su itinerario estético, piensa el futurismo italiano dentro y fuera de sus coordenadas productivas específicas, vale decir, en y más allá de su locación ideológica, abriendo un campo de entendimientos estéticos y artísticos ubicados entre militancias políticas concretas y búsquedas de vuelos futuristas. En el presente escrito, se abordan textos que Mariátegui realizó en pleno auge del futurismo, en medio de la contingencia histórica latinoamericana y europea, operando en la articulación de un horizonte mítico continental.
\end{abstract}

Palabras clave

Futurismo, Latinoamérica, horizontes míticos, arte, revolución, fascismo.

\section{José Carlos Mariátegui and Italian Futurism: A Latin American Perspective}

José Carlos Mariátegui was a Peruvian intellectual, politician, and cultural activist engaged in understanding and promoting the avant-garde from a Marxist Latin American perspective. In his aesthetic itinerary, he reflects on Italian Futurism from all angles of its specific productive coordinates, within and beyond its ideological location. In doing so, he inaugurated a field of aesthetic and artistic knowledge located between concrete political affiliations and explorations for futuristic fantasies. This article discusses texts that Mariátegui wrote at the peak of the futurism movement, amidst Latin American and European historical contingency, articulating a mythical continental horizon.

Keywords

Futurism, Latin America, mythical horizons, art, revolution, fascism.

* Recibido: 30 de agosto de 2016 / Aceptado: 14 de octubre de 2016. 


\section{José Carlos Mariátegui e futurismo italiano: uma perspectiva latino-americana}

\section{Resumo}

José Carlos Mariátegui era um ativista intelectual, político e cultural peruano envolvido na compreensão e promoção da vanguarda de uma perspectiva marxista latino-americana. Em seu itinerário estético, ele reflete sobre o futurismo italiano sob todos os ângulos de suas coordenadas produtivas específicas, dentro e além de sua localização ideológica. Ao fazer isso, inaugurou um campo de conhecimento estético e artístico localizado entre afiliações políticas concretas e explorações para fantasias futuristas. Este artigo discute textos que Mariátegui escreveu no auge do movimento futurista, em meio à contingência histórica latino-americana e européia, articulando um horizonte continental mítico.

\section{Palavras-chave}

Futurismo, América Latina, horizontes míticos, arte, revolução, fascismo. 


\section{El futurismo italiano y América Latina (a modo de introducción)}

A Mariátegui le resultaba interesante la actitud, el ímpetu futurista como muestra de ruptura con la linealidad histórica (que recuerda por un momento cierto romanticismo nietzscheano tan cercano al autor), en busca de un futuro utópico. Sin embargo, no se identificaba con su horizonte político: "El programa político del futurismo constituyó una de las desviaciones del movimiento, uno de los errores mortales de Marinetti. El futurismo debió mantenerse dentro del ámbito artístico [...]" (1977: 58).

El futurismo abarcó distintas prácticas estéticas, como la poesía, la arquitectura, la escultura, la pintura y, en alguna ocasión, la música. En el caso de la pintura, se presentaba como un desafío el traducir la simultaneidad y el dinamismo de la vida moderna en una superficie fija, estática.

Las características formales del futurismo se enmarcaban en una búsqueda desesperada por resolver estéticamente lo que se exhibía en manifiestos constantes y determinantes. La cuestión era compleja porque el futurismo hablaba con devoción de las cristalizaciones de la revolución industrial, buscando poéticas en las máquinas, en los automóviles, en sus ruidos y olores: "nos aproximamos a las tres máquinas refunfuñantes para acariciar sus petrales"; o bien, "oh fosa maternal medio llena de agua fangosa. Oh zanja de desagüe de una fábrica", escribió el fundador del futurismo italiano Filippo Tommaso Marinetti junto a sus amigos, en el manifiesto "Le Futurisme", publicado en Le Figaro el 20 de febrero de 1909 (Martín, 2005: 8).

Lo curioso, por decirlo de alguna forma, es que Marinetti, que prestaba tanta atención poética a las fábricas, no puso su atención en los trabajadores de la fábrica. De alguna manera, podríamos decir que fetichizó estos signos de la revolución industrial, configurándolos como objetos de culto. Es posible, en este sentido, que la huida de Marinetti hacia el futurismo italiano no haya sido tanto del pasado y de la tradición como, más bien, de lo humano, del cuerpo sensible ${ }^{1}$.

\footnotetext{
${ }^{1}$ Esta huida del cuerpo sensible es una tradición instaurada por la lógica racional, como un ideal a cumplir en la operación cognitiva, el abandono emocional, el abandono de lo oculto en el cuerpo -Observar la emoción como un "estado del soma" (Damasio, 2006), en donde se hace evidente un horizonte ideológico masculinizado, que rigidiza cualquier presente en pos de su instalación en alguna epistemología, que por rígida, también muerta. Apareciendo como una especie de sinsentido epistemológico en la fetichización de la existencia, en la auto-complacencia (metáfora concupiscente) estético- intelectual. La visión de la realidad vertida siempre hacia fuera, en donde se condensa un agotamiento de vida. La realidad, en la perspectiva vívida y poética de análisis, funciona dialécticamente en su realización hacia fuera y también hacia dentro, cuya retroalimentación simultanea, decanta en el cambio constante, en la apertura hacia lo inesperado, lo desconocido, que finalmente, habita en la oscuridad habitable del cuerpo. Esto se relaciona con la dicotomía
} 
Es sabido que el futurismo, a través de sus manifiestos, llamaba a que la mujer no se comportase "sentimentalmente", instándola, además, a llenarse de virilidad. De hecho, el futurismo llamaba a una sociedad no feminizada, sino virilizada (Saint-Point, 2010). La razón puede ser clara. La visión del futurismo era la de una flecha en dirección hacia adelante, apuntando hacia el futuro, de manera similar al signo del sexo masculino, mientras que lo femenino, entendido como lo que da lugar al ciclo y al encuentro con el misterio, se percibía como obstrucción a este avance (es decir, a la linealidad de la historia). Desde este punto de vista, el futurismo italiano se localizaba en las coordenadas de un objeto futurista definidas desde el pasado (la ausencia de presente definiría su obsesión por el futuro). La fetichización de la máquina y todos sus despliegues estéticos estarían en relación directa con la masculinización del pensamiento y la percepción como una negación hacia lo misterioso, lo curvo, lo oscuro e insondable que representaba lo femenino (Aksman, 2010).

Desde el primer manifiesto de Marinetti publicado en la revista Le Figaro de París, en febrero de 1909, solo transcurren dos meses para que en América encuentre una reacción. Uno de los primeros críticos del futurismo fue el poeta nicaragüense Ruben Darío, quien publica en La Nación de Buenos Aires, el 5 de abril de ese mismo año, un texto titulado "Marinetti y el futurismo". En él, hace notar que "el Futurismo estaba ya fundado por el gran mallorquín Gabriel Alomar...", planteando una crítica a la lineal esperanza en un futuro mesiánico: "¿no será lo mismo ir hacia adelante que hacia atrás? [...] lo único que encuentro inútil es el manifiesto" (Darío, 1988: 6). El 6 de abril (un día después), el escritor portugués Manuel Sousa Pinto, corresponsal de Correio da Manhã, publica "O futurismo (À hora do correio)", donde presenta el futurismo como una provocación extravagante realizada por un "grupo de artistas incipientes" con prosa "niilista e imberbe", como fruto de una "temerosa indigestão de Niestzsche, Wagner e Savonarola" (Fabris, 2011). El manifiesto Futurista traducido desde el italiano sería publicado en Brasil en el Jornal de Noticias de Bahía el 30 de diciembre, bajo el título "Uma nova escola literaria", por Alquimio Diniz, donde el mismo traductor menciona como algo interesante del movimiento el concepto en torno a "a beleza da velocidade (...) porque a beleza debe expandir-se tanto mais no espaço quanto seja aproveitada no menor tempo" (Fabris, 2011).

Dentro de estas coordenadas discursivas, el futurismo se anunciaba mediante un plan de acción intempestivo, provocativo contra la tradición, frente a la cual, más que generar una "dislocación", pretendía desatar un desorden, una especie de anarquía. Este plan de acción fue seguido o copiado, por ejemplo, en Brasil, 
donde, llamado por Oswald de Andrade "futurismo paulista", buscaba declarar una rebeldía contra cualquier dogma en pos de una libertad creativa y un "sentimiento estético" propios, excluyendo de esto incluso al propio Marinetti. Anita Malfatti y otros artistas que participaron en la Semana de Arte Moderno de 1922, fueron tachados de futuristas no porque hayan sido parte del movimiento, sino porque su obra se alejaba de los cánones artísticos nacionales y, específicamente, debido a una declaración de Oswald de Andrade para Mario de Andrade titulada "Meu poeta futurista". Para aclarar que no había futuristas en el movimiento modernista, se replicó posteriormente que "Futurista passou a ser, como diz Mário da Silva Brito, o 'denominador común' para tudo quanto 'pareça diferente, inusitado'” (Amaral, 2010: 118). Estos debates intensos en la muestra de São Paulo de 1922 ocuparon los principales medios de prensa para difundir sus discusiones e interrogantes. El futurismo paulista se hizo parte de este culto a la técnica y a la velocidad que se configuraba en su manifestación estética como ruptura y corte, según quedaba de manifiesto en la revista Klaxon. De esta forma, hacían parte del movimiento modernista, tomando para sí el concepto de construcción del futuro, más que de destrucción del pasado, y permitiéndose contextualizarse nacionalmente y orientarse en las coordenadas de una estética experimental influenciada por el antipositivismo y por la corriente nietzscheana (también tomada por el futurismo), que, luego, tomó forma en la conocida Antropofagia artística de Brasil².

En México se dio el estridentismo, cuyo manifiesto aparece en el año 1921, siendo publicado por el poeta Manuel Maples Arce en la revista Actual n. 1 con el subtítulo de "Hoja de Vanguardia. Comprimido estridentista de Manuel Maples Arce". El estridentismo se articulaba desde las coordenadas estéticas del creacionismo de Huidobro, el ultraísmo de Guillermo de Torres y el dadaísmo de Tristan Tzara, pero también, más enfáticamente, del futurismo. Celebraba la juventud, el antipasadismo, las tecnologías, la velocidad vertiginosa y la agitación subversiva de la vida contemporánea. Los estridentistas decían, por ejemplo, “iChopin a la silla eléctrica!", siendo sus principales animadores poetas y literarios. La experiencia estridentista duró menos de una década (Rashkin, 2015).

En Cuba, la conciencia sobre una nueva época en la vanguardia artística iba encontrando espacio a partir de 1927 en la Revista de Avance, que incluía colaboradores cubanos y extranjeros. Esta revista fue canalizando la expresión del Grupo Minorista, que promovía los cambios estéticos de la vanguardia de los años 1920 en su país, caracterizada por una fuerte carga ideológica y por sus aperturas hacia lo social. La Revista de Avance estaba en diálogo con la mexicana El machete, la

\footnotetext{
2 "A pecha de futuristas continuaba sendo dada aos modernistas. Mário em vão tentou desfazer o equívoco: 'Á erronia, é verdade, começou por nós. Oswald de Andrade chamou-nos futuristas um dia...." (Amaral, 2010: 138).
} 
argentina Martín Fierro y la peruana Amauta, lo que la situaba dentro del debate internacional sobre las vanguardias. Las imágenes publicadas eran confluyentes de Argentina, España, Estados Unidos, Francia, Guatemala, México, El Salvador, Rusia, Uruguay y Venezuela (Sartor, 2012). Estas imágenes sintetizaban los lenguajes y recursos plásticos del cubismo y el futurismo, con un fuerte acento ideológico. Claro que las repercusiones del futurismo en América Latina eran apoyadas o construidas desde sectores de izquierda, acorde con el futurismo ruso, que era prioritariamente literario.

En Chile, Vicente Huidobro se hizo parte del debate en torno al futurismo inicialmente en su revista Azul, aparecida en 1913, y luego en el libro Pasando y pasando... Crónicas y comentarios, de 1914. En él, observó críticamente, por ejemplo, que "declararle guerra a la mujer, aparte de ser una cobardía impropia de hombres tan vigorosos como los futuristas, es una gran ridiculez" (1914: 167). Además, escribió en torno a la creación de la realidad en su Manifiesto de Manifiestos: "hay que pulsar los hilos como las cuerdas de un arpa, y producir una resonancia que ponga en movimiento a las dos realidades lejanas. La imagen es el broche que las une, el broche de luz..." (Huidobro, 1989: 322; Ortega, 2000: 191). Exponía ya en estos términos su teoría del creacionismo, según la cual el mundo debía reinventarse en oposición al realismo (poietés, hacedor de una nueva realidad), pues "el poeta crea fuera del mundo el que debiera existir..." (Huidobro, 1989: 294). En ese mismo periodo se realiza en Valparaíso la primera obra futurista musical, titulada Paseo en góndola, cuyo autor fue Pablo Garrido. Aunque no contamos con mayores detalles sobre ella, la obra habla de la rumorosidad de un viaje en estos inestables y precarios medios de transporte chilenos ${ }^{3}$.

Las raíces italianas de los argentinos pueden explicar que tanto ellos como los uruguayos viajaran y habitaran con tanta familiaridad en Italia. Destacan en esto los artistas Xul Solar, Emilio Pettoruti, Rafael Pérez Barradas y el escultor Pablo Curatella Manes, apareciendo también en Europa el uruguayo Joaquín Torres García. Barradas realizó una exposición en una galería en España llamada Dalmau, donde expuso obras "vibracionistas" que giraban en torno a la vida ciudadana en la calle y fundían el simultaneísmo de los cubistas franceses y el dinamismo de los futuristas italianos (en particular de Severini). En este vibracionismo de ideas que fue difundido entre revistas de vanguardia (Arc Voltaic) y galerías, emergía y se

\footnotetext{
${ }^{3}$ En el campo musical en nuestro país se produce una curiosa simultaneidad, entre 1900 y 1921 se estrena la primera sinfonía romántica chilena de Enrique Soro, quién tenía una completa formación en Italia. A la vez, Alfons Lenk, del grupo de Los Diez, estrena su obra Alcino, que representa la atmósfera de corte impresionista y evoca al Debussy del poema sinfónico del mar. De manera que en Chile, en el año 1920, ingresan simultáneamente, cánones artísticos musicales intensa y temporalmente distanciados Entre el romanticismo de Bethoven y el poema sinfónico de Debussy transcurre un siglo (Torres, 1991).
} 
difundía también el ultraísmo (con las revistas Ultra y Gaceta Literaria), como movimiento liderado por escritores y poetas. Claramente, en las posturas ultraístas, aparecen las vibracionistas y viceversa. Tendieron amistad Guillermo de Torres, redactor del manifiesto ultraísta, con Barradas, vibracionista, y, luego, con Huidobro, creacionista (Sartor, 2012).

Los artistas latinoamericanos como Xul Solar o Pettoruti, al regresar, fueron alimentando un nuevo ciclo artístico en su país, marcado por un arte internacionalista. Martín Fierro, Proa, Inicial fueron claramente espacios de difusión de la vanguardia europea. En 1920, se publicaba el único número de la revista Los raros, dirigida por Bartolomé Galindez, que difundía el ultraísmo y tenía un claro matiz futurista. En 1921, Borges publicaba su distanciamiento del futurismo italiano y del ultraísmo español (Sartor, 2012)...

Florencia era un epicentro de artistas e intelectuales antípodas visibilizados por medio de dos revistas, La voce y Lacerba. El clima era de un futurismo militante encendido, presto para la guerra. El argentino Petorutti tuvo un collage publicado en la revista futurista Lacerba, llamado "El sifone". Sin embargo, este artista nunca definió su obra dentro de alguna vanguardia. Nunca quiso adherir formalmente al futurismo. Tuvo contactos con Severini y se interesó en la obra cubista de Juan Gris. Tuvo un itinerario autónomo en sus búsquedas estéticas.

En 1926, Marinetti visitó Argentina, en donde, por medio de periódicos rioplatenses, era llamado político y filofascista. Además, era definido como un "hombre superficial" y un "ardiente propagandista", pero de ninguna manera como un artista, un lírico o un crítico (Fabris, 1990; Saitta, SF: 168-169).

En 1913 aparece la publicación del segundo programa político del futurismo en la revista Lacerba (Florencia), donde se destacaba "la defensa del individualismo y... del irredentismo italiano en las zonas italohablantes, el odio visceral hacia el socialismo y el anticlericalismo" (Méndez, 2013). En 1920 se agudizan estas declaraciones en la la publicación llamada Ideas Fundamentales del Futurismo, llevándolas a propuestas concretas como, por ejemplo, "creación de un ejército de voluntarios para la modernización del servicio de seguridad pública y gobierno de Italia a cargo de jóvenes militantes" (Martin, SF, pág. 22). La relación entre el futurismo y el fascismo fue abordada explícitamente por el mismo Marinetti en su libro Futurismo y fascismo, del año 1924, en donde va mostrando los puntos de contacto entre ambos (Martín, 2005). Luego, estando ya prácticamente al servicio de Mussolini, Marinetti fue tomando distancia del futurismo, transigiendo por cálculos políticos en cuestiones claves del movimiento, como su animadversión contra el cultivo directo del pasadismo, y acercándose de esta forma a la iglesia católica, así como a la misma academia. 
Artistas de la segunda fase del futurismo realizaron muestras sobre el estado fascista como "Mostra della Rivoluzione fascista" (Exposición de la revolución fascista) realizada en Roma en 1932. La primera parte del futurismo fue analítica y destructiva y, después de la primera Guerra Mundial, se desarrolló una fase sintética y constructiva (espacialidad nítida y volúmenes elementales). Ya sin la presencia directa de Marinetti, el futurismo italiano tomó una vía interdisciplinar, enfocándose en la arquitectura y el diseño de interiores, mientras que en las artes plásticas aparece la aeropintura como una tabla de salvación estética (Martin, SF: 24-25).

\section{Mariátegui y el futurismo}

En 1919, Mariátegui fue forzado a viajar a Europa, directamente a Italia, por ser considerado un agitador político-cultural peligroso para la tranquilidad del Oncenio del Presidente Augusto Leguía. Este viaje fue trascendental para el cronista, ya que le permitió conocer directamente a los artistas y la corriente vanguardista europea, especialmente el futurismo, el dadaísmo y el surrealismo. En este contexto de vanguardias artísticas y políticas, Mariátegui, siendo un hombre político, se sitúa en el mundo del arte desde la heterodoxia. No sanciona ciegamente el futurismo por su adhesión histórica al fascismo, sino que lo observa desde su motivación profunda.

En varios textos Mariátegui toca el tema y se podría decir que el vórtice que le permite pensar el futurismo desde un punto de vista latinoamericano es la cuestión del mito. Sus lugares de encuentro con el futurismo están trazados por algunos conceptos que, en términos generales, parecen funcionar, aunque luego Mariátegui, al profundizar en ellos, les va quitando el velo conceptual, explicando la profundidad del sentido mítico.

Uno de los términos que trabaja Mariátegui en su obra es el pasadismo, como añoranza paralizadora, sofá perfecto donde descansar del mal ánimo y justificación de una inercia ante el presente. Como desazón ante el porvenir. Por otra parte, Marinetti critica el pasadismo como una forma de rechazo a las tradiciones y los dogmas. En Peruanicemos el Perú, Mariátegui escribió que "la verdadera tradición está invisible, etéreamente en el trabajo de creación del orden nuevo" (1986: 213), refiriéndose así a la cultura del pueblo, que abriga el mito y su praxis ritual de lucha, mediante la formación de una autoconciencia histórica en la construcción incesante de su tradición. El aliado del criollo nacionalista, que se resiste a la influencia de ciertos aspectos de la internacionalización, es la tendencia a ignorar lo evidente, a acomodarse en una "pereza mental" y una "insensibilidad moral" (42). Ya que ignora la realidad decididamente, este nacionalismo se traduce en pura abstracción, generando el mito ficticio del fascismo. 
Entonces, Mariátegui, por una parte, recalca el hecho de que lo artístico es rupturista, pero, por otra, problematiza la distancia entre el dogma y el dogmatismo, así como entre la tradición y el tradicionalismo, y la cuestión iconoclasta como un método propositivo dislocador enfocado en el presente, no como un fin en sí.

La principal crítica que hace al futurismo italiano se ancla en la cuestión mítica, ya que el arte revolucionario, para Mariátegui, debe tener un horizonte mítico, mientras que, en el caso del futurismo italiano, pese a su iconoclastia, se forma, desde la imagen mítica del futuro, el ansia de un ideal fascista volcado hacia el pasado. Así, caracterizándose por la ruptura con el pasado en la práctica de difusión, el impulso teórico del futurismo proviene de una mitología estancada ${ }^{4}$. Precisamente, el futuro como idea es lo que se pone sobre la mesa; el futuro con todo lo que trae consigo: la línea de tiempo, el paso, el presente. La rebeldía del futurismo coincide con esta necesidad de "interrumpir la historia", como dijera Walter Benjamin (Galende, 2009) y crear el futuro en la dislocación del presente. Sin embargo, las cuestiones que permiten configurar la ruptura y la creación van ligadas al imaginario.

La cuestión del horizonte mítico es planteada por Mariátegui mediante metáforas que aluden a la constante actualización del mismo. Aunque parezca contradictorio, hay una coherencia unitaria en este concepto, "pues mitología y poesía son ambas una unidad indivisible" (Schlegel, 1994: 119). Para Mariátegui, el mito refiere, por una parte, a una memoria en espera de ser perpetuada mediante una praxis ritual que renueve la fe en este mundo simbólico contenido estéticamente. El símbolo, cual "tablilla del recuerdo" ${ }^{5}$, aparece como una especie de contrato trans-gene-racional que, instalado justo al frente, hacia el lugar en donde soñamos y proyectamos todo, genera una operación estética interna que consiste en una mantralización de un anhelo colectivo. Por otra parte, sin embargo, Mariátegui insiste en que este círculo mítico en donde la tradición se asegura y afirma en el futuro a través de la ritualización del presente estético, debe ser accionado integrando constantemente la propia experiencia, el pathos, de manera que exista una cierta vitalidad, fluidez y apertura (en tiempo presente) de un horizonte

\footnotetext{
${ }^{4}$ Para complementar la comprensión de la "autoconciencia" aquí mencionada, se recomienda revisar el concepto de cultura aludido por Antonio Gramsci (1998).

${ }^{5}$ Con respecto al significado del término símbolo, Gadamer lo indica como: "tablilla del recuerdo», refiriéndose a aquel trozo de tablilla que -luego de ser dividida en dos partes- el anfitrión le obsequiaba a su huésped a fin de reconocerse con el paso de los años mediante la unión de sus piezas. Dicha tablilla era denominada tessera hospitalis, o testigo de la hospitalidad, y constituye para el autor una suerte de pasaporte en la época antigua en virtud de que propicia el reconocimiento de viejas amistades. "La tessera hospitalis es un resto de una vida vivida en otro tiempo, y atestigua con su existencia aquello a lo que se refiere, es decir, deja que el pasado se vuelva presente y se reconozca como válido" (Gadamer, 1984: 204205).
} 
que aparentemente es rígido (es decir, que, indicando hacia un pasado, sugiere un futuro).

De aquí que Mariátegui subraye la diferencia entre dogma y dogmatismo y aluda al fascismo como un ejemplo en donde se afirma un horizonte mítico anacrónico, trayendo solamente en esta rigidez destrucción y muerte. La actualización del mito no sólo trae destrucción y muerte (en el caso de que lo implique), sino que el fin constante es la vida y la creación. La negación no funciona sólo como negación, debe traer consigo la afirmación:

Ninguna ánima, ni aun la más nihilista, se contenta ni se nutre únicamente de negaciones. La nostalgia del pasado es la afirmación de los que repudian el presente. Ser retrospectivos es una de las consecuencias naturales de ser negativos. Podría decirse, pues, que la gente peruana es melancólica porque es pasadista y es pasadista porque es melancólica (Mariátegui, 1986: 29).

Un horizonte mítico anacrónico es insuficiente e improductivo y genera manifestaciones que perpetuán lo mismo. A este fenómeno social, Mariátegui le llama "pasadismo incurable y enfermizo" (Mariátegui, 1986: 26). La poesía y el arte que están vivos (espontáneos, fecundos, biológicos) existen en un horizonte mítico espiritual en constante revisión y autoconciencia, lo que implica que se centran en el mismo presente que los produce:

Por ende, sólo concibiendo a la nación como una realidad estática se puede suponer un espíritu y una inspiración más nacionales en los repetidores y rapsodas de un arte viejo que en los creadores o inventores de un arte nuevo. La nación vive en los precursores de su porvenir mucho más que en los supérstites de su pasado (103).

Entonces, el mundo simbólico de un horizonte mítico activo emerge con la finalidad de anticipar el futuro (conscientemente o no) desde la praxis del presente ${ }^{6}$, lo que, llevado a un plano social, decanta en una praxis revolucionaria, porque actualiza el poder individual en su quehacer colectivo. Esto, lógicamente, parece contradictorio, pues en este "decir" y "mostrar" las figuraciones del discurso poético, se tensiona la compresión racional en la imposibilidad cartesiana de tal fenómeno espiral de la amplificación de la conciencia.

Mariátegui subraya que esta ampliación del horizonte debe ser dada con una ubicación fuera de la "torre de marfil", con la intención de ampliar el radio sensible figurado estéticamente. Se aproxima de esta manera a la construcción de una conciencia colectiva desde esta praxis artística:

\footnotetext{
6 "Símbolo vivo es aquel que también para el que considera constituye la expresión mejor posible suprema de lo presentido, más no conocido aun. En circunstancias tales, da lugar a una participación inconsciente. Produce un efecto vitalmente creador y estimulante" (Jung, 1937: 505).
} 
Algunos artistas de la nueva generación comprenden ya que la torre de marfil era la triste celda de un alma exangüe y anémica. Abandonan el ritornello gris de la melancolía, y se aproximan al dolor social que les descubrirá un mundo menos finito. De estos artistas podemos esperar una poesía más humana, más fecunda, más espontánea, más biológica (27).

El pensamiento racional, al intentar conocer el mito, le desnaturaliza, tras la insistencia en sistematizar el relato de la existencia. El mito es inaprensible racionalmente: en la medida en que se va conociendo científicamente (separadamente) se va perdiendo; en la medida en que se lo va investigando, se lo va destruyendo ${ }^{7}$.

Para el mundo mítico, el conocimiento de la vida ${ }^{8}$ logra ser desprendido en la experiencia ritual del mismo. Pensado en la metáfora de esta operación y sin el ánimo de hacer una apología al pensamiento mítico, podemos pensar que pretender conocer o racionalizar un mito encuentra una equivalencia en pretender separar el arte de su momento aurático ${ }^{9}$, donde el arte pierde su poética activa (viva) y queda rígido como fetiche en su forma muerta, vacía. Estos fetiches son los que constituyen, para el futurismo italiano, la figuración de su horizonte mítico, de manera de excluir del presente cualquier manifestación sensible, oscura, dudosa. Recordemos la crítica que hace Walter Benjamin al futurismo italiano, diciendo que esta propuesta manifiesta el apoyo al despojo de toda cuestión aurática, a cualquier experiencia no seriable cuyo eje central sería el goce de la autodestrucción humana por medio de la máquina:

La humanidad que antaño en Homero, era un objeto de espectáculo para los dioses olímpicos, se ha convertido ahora en espectáculo de sí misma. Su autoalienación ha alcanzado un grado que le permite vivir su propia destrucción como un goce estético

\footnotetext{
7 "Por demasiado analizar el símbolo, por incorporarlo demasiado estrechamente a una cadena (rayo, nube, Lluvia, toro, fecundidad, etc) por reducirlo demasiado a una unidadlógica, se corre el riesgo de hacerlo desvanecer: no tiene peor enemigo que la racionalización.... Analizar intelectualmente un símbolo, dice Pierre Emmanuel, es pelar una cebolla para encontrar la cebolla ... él no existe más que en lo inaprensible que lo funda" (Chevalier, 1986: 35).

8 "En efecto, la mitología reúne los mitos de todas las edades y de todos los orígenes, pero desprendidos de su contexto vívido, es decir, desnaturalizados. La empresa misma de una mitología es un acaecimiento de época posterior. Traduce una iniciativa reflexiva, un deseo de sistematización que es todavía extraño al hombre de la edad mítica. Para él, el mito no es un mito, sino la verdad misma" (Gurdorf, 1970: 13).

9 "La percepción de un símbolo, la epifanía simbólica, nos sitúa, en efecto, en un cierto universo espiritual. Por eso jamás conviene 'separar los símbolos de su acompañamiento existencial; ni jamás suprimir el aura luminosa en cuyo seno nos han sido revelados, por ejemplo en el gran silencio sagrado de las noches, cara al firmamento inmenso, majestuoso, arrobador" (Champeaux; Sterckx, 1966: 49). Imposible no recordar a Walter Benjamin con su texto "La obra de arte en la época de su reproductibilidad técnica" (1989: 17-59).
} 
de primer orden. Este es el esteticismo de la política que el fascismo propugna. El comunismo le contesta con la politización del arte (Benjamin, 1989: 57).

Se entiende, entonces, que el futurismo italiano estaría constituido (como toda realidad) por contradicciones, ya que combate un pasadismo, indicando un futuro, y fetichiza los signos de la Revolución Industrial, operando sobre ellos desde una búsqueda poética que exalta de alguna manera una cierta belleza, como una oda a la misma destrucción del futuro por medio de la saturación industrial. La obsesión de enaltecer la muerte ratifica que la destrucción era su único fin, siendo cualquier acto creativo un medio para ello. Entonces, este futurismo funcionaba como un operativo estético del fascismo.

Por medio de la destrucción, el futurismo arrebataba cualquier futuro al presente, razón por la cual se caracterizó por su incapacidad para activar humanamente la propuesta de productividad técnica ${ }^{10}$ (Benjamin, 1989: 55-57). En una sociedad hiper-racionalista, el arte es visto como fetiche, cual objeto a consumir, por tanto, a deshechar, desintegrar, desmembrar (dependiendo del enfoque), y no como un fenómeno a percibir-experimentar ${ }^{11}$. En una carta dirigida a Trotski en torno al futurismo italiano, Antonio Gramsci menciona la situación de Marinetti en el contexto fascista, diciendo que "los representantes principales del futurismo antes de la guerra se han hecho fascistas, con la excepción de Giovanni Papini, que se ha convertido al catolicismo (...)" (Gramsci, 1964).

La permanencia de la obra de arte como cosa instala al sujeto frente a un objeto rígido, extraído de su fenómeno artístico que funciona como la osamenta de una mítica anacrónica. Por tanto, se le extirpa, mediante la temporalidad, lo artístico a la obra. Así, la actualización del mito refiere, en Mariátegui, a que el arte debe

\footnotetext{
${ }^{10}$ Hay una relación entre José Carlos Mariátegui y Walter Benjamin que el tiempo ha ido permitiendo leer. La perspectiva mítica-mística que, de acuerdo a las coordenadas religiosas de cada cual, atravesaba discursiva o estéticamente su obra (Löwy, 2012). Por otra parte, el método escriturario, mostrándose fragmentario y heterodoxo en la forma de citar o de realizar cruces epistemológicos, otorgó a su pensamiento posibilidades de profundizar la realidad desde una flexibilidad afirmada en poéticas discursivas. En torno a esto, hay diversos textos que lo han analizado (Mazzeo, 2012; Figueroa, 2012) y sin duda es un tema a profundizar.

${ }^{11}$ Hay una sintonía con Lefevbre cuando éste escribe en torno a la agotabilidad de la lógica y el lenguaje: "EI lenguaje está fetichizado, se lo considera como una especie de absoluto, como la fuente no solo de la inteligibilidad sino de la vida social.... Este fetichismo en muy viejo. Va junto precisamente con la ruptura entre los significantes y los significados que yo invocaba hace poco.... Hay entonces un fetichismo del lenguaje y al mismo tiempo una extraordinaria disolución del lenguaje bajo los embates más variados: los medios audiovisuales, una utilización virtuosa, y acrobática del lenguaje. ... Ustedes habrán visto los millones o miríadas de sonetos obtenidos con la combinación de alejandrinos que pueden agruparse arbitrariamente. ... La primera línea: 'Doucékipudonktan' es la muerte del lenguaje. Al mismo tiempo que algo se fetichiza, se pierde" (Lefebvre, 1973: 104).
} 
estar vinculado a conceptos como "presente", "revolución", "vanguardia", "mito", "porvenir", "espíritu": "Una nueva escuela, una nueva tendencia literaria o artística busca puntos de apoyo en el presente. Si no los encuentra perece fatalmente. En cambio, las viejas escuelas, las viejas tendencias se contentan de representar los residuos espirituales y formales del pasado" (Mariátegui, 1986: 103).

El futurismo, visto desde esta bio-estética ${ }^{12}$, aparece, para Mariátegui, no sólo en su modo literario y artístico, sino también como actitud espiritual que da cuenta del impulso colectivo profundo de ese presente, a partir de la representación de la conciencia italiana. El artista, en su praxis, contiene esta fuerza del presente colectivo en una actitud iconoclasta rotunda. El horizonte mítico de una sociedad influye en el arte de su época definiendo o potenciando los elementos estético y espirituales afines:

El estudio de la biología del futurismo italiano conduce irremediablemente a esta constatación. El futurismo ha representado, no como modalidad literaria y artística, sino como actitud espiritual, un instante de la conciencia italiana. Los artistas y escritores futuristas, insurgiendo estrepitosa y destempladamente contra los vestigios del pasado, afirmaban el derecho y la aptitud de Italia para renovarse y superarse en la literatura y en el arte (...). Cumplida esta misión, el futurismo cesó de ser, como en sus primeros tiempos, un movimiento sostenido por los más puros y altos valores artísticos de Italia (72-82).

El horizonte mítico mariateguiano refiere a un estado de comprensión poético de la existencia en donde el sentido de la vida y de la muerte es vital y colectivo. La posibilidad de creer, construir, destruir y volver a crear a partir de lo que se es, está en sintonía con la problematización de la tensión existente entre el mundo de la lógica y la mística de la praxis política, estética y artística. El pensamiento mítico posibilita un método para comprender la realidad que salta entre el terror y la poesía: por una parte, muestra un estado de cosas no deseadas; por otro, abre la imaginación para una apropiación de la realidad por medio de la adquisición de auto-conciencia, colectiva e individualmente. Una especie de elevación teomorfa del hombre (Blumemberg, 2004: 15).

La orientación espiritual de nuestro autor no es producto de una fe ciega. Para Mariátegui, la vida espiritual afectaba directamente la vida material. Mariátegui se encargaba de traer en el cotidiano "el cielo a la tierra" (Mariátegui, 1975: 198), una idea terrena de lo divino, hacia la conformación racional y mítica de un Dios de la praxis. De manera que, políticamente, se podía traducir esta espiritualidad

12 "El arte tiene un contenido biológico ¿cómo se determina ese contenido? El mismo impulso sexual, sobre todo, aporta un elemento vivo indispensable a muchas obras de arte. Una estatua se contempla, una novela se lee, con todo el ser (y no con toda el alma como decía Platón)..." (Lefebvre, 1971: 79). 
en la construcción de una especie de nacionalismo internacionalista, llamando a la solidaridad entre pueblos, de carácter interclasista y, estéticamente, en las coordenadas de un método poético para comprender la historia. Esta actitud espiritual sostenida racionalmente, permitía que su pensamiento estético tuviera una traducción política, como también, que su pensamiento político tuviera una traducción estético-artística, ya que, en ese intercambio dialéctico, emergía la fuerza del mito por medio de la pregunta constante por el sentido del mismo hacia un horizonte determinado (que se activaba en cada momento, y en cada momento a su vez variaba).

De ahí que Mariátegui hablara del empoderamiento anímico del indio, de la emoción colectiva, del sentimiento ante la vida. Así, la emoción revolucionaria significaba necesariamente un renacer espiritual guiado por la brújula interior, cual pulsión interna y fuerza intuitiva. El autor dice lo siguiente:

El futurismo se hizo fascista porque el arte no domina a la política. Y, sobre todo, porque fueron los fascistas quienes conquistaron Roma. Mas con idéntica facilidad, se habría hecho socialista, si se hubiese realizado victoriosamente, la revolución proletaria. Y en este caso su suerte habría sido diferente. En vez de desaparecer definitivamente, como movimiento o escuela artística (esta ha sido la suerte que le ha tocado al fascismo), el futurismo habría logrado entonces un renacimiento vigoroso. El fascismo, después de haber explotado su impulso y su espíritu, ha obligado al futurismo a aceptar sus principios reaccionarios, esto es a renegarse a sí mismo teórica y prácticamente. La revolución, en tanto, habría estimulado y acrecentado su voluntad de crear un arte nuevo en una sociedad nueva." (Mariátegui, 1986: 103-104).

Insistimos en la importancia de la actualización de imaginarios míticos en Mariátegui porque ellos serían el fruto de una tensión constante entre el sujeto y la realidad viva en la que éste está inmerso. La realidad, como forma, contiene en movimiento constante su idea (pues se conciben mutuamente), y el malestar de la cultura, en Mariátegui, tiene que ver con el desajuste y la anacronía entre la forma impuesta y su contenido vivo, que, a su vez, dice relación con la necesidad de actualizar el mito en la praxis ritual de su manifestación estética (Mariátegui, 1970: 3-35).

El factor rígido del horizonte mítico del futurismo se des-enmarca de lo circular, para guiarse únicamente por una flecha viril que produce el quiebre, la derrota. Debido a esto es que, por una parte, Marinetti ocupaba como medio de difusión, por decirlo de una manera lógica, la interrupción de los espacios y los escándalos, pero luego no encontraba una resolución estética y artística de este discurso in- 
cendiario. Estas acciones eran vacías de un propósito profundo, en el sentido mariateguiano, ya que la negación no funciona únicamente como negación ${ }^{13}$. La dialéctica de la realidad incorpora y exige la integración de la afirmación y la negación, de manera que ni la afirmación ni la negación sean un fin en sí mismas, sino estados procesuales que permiten la fluidez y los desplazamientos constantes hacia un horizonte intangible, pero en constante afluencia de realidades.

Así, la dislocación como acto estético forma parte de la concepción de un arte revolucionario, pero sólo como un medio para que el dislocado active su yo profundo para la creación de presentes anclados en un horizonte mítico colectivo que permita vivir un equilibrio evolutivo social. Entonces, el futurismo anclado en un horizonte mítico rígido que declara para sí la virilidad como único camino a un futuro revolucionario, urde su propio fin, pues niega la parte de la realidad que es, precisamente, la que permite el pensamiento creativo, mítico y sensible, ubicado en el cuerpo -esa zona oscura, indescifrable-, y que otorga la posibilidad de gestar el futuro en medio de un presente huidizo porque impredecible. Así, el futurismo italiano condensa su discurso en la superficie de la realidad y lo estetiza en esa flecha viril que indica un futuro inexistente.

\section{Referencias}

Amaral, Aracy (2010). Artes Plásticas na Semana de 22. São Paulo: 34.

Benjamin, Walter (1989a). La obra de arte en la época de su reproductibilidad técnica. Buenos Aires: Taurus.

(1989b). Discursos interrumpidos. Buenos Aires: Taurus.

Blumenberg, Hans (2004). El mito y el concepto de realidad. Barcelona: Herder.

Champeaux, Gerard de; Sterckx, Dom (1966). Introducción al mundo de los símbolos. Barcelona: Juventud.

Chevalier, Jean (1986). Diccionario de los símbolos. Barcelona: Herder.

Damasio, Antonio (2006). El error de Descartes: La emoción, la razón y el cerebro humano. España: Crítica.

\footnotetext{
${ }^{13}$ Que la negación no funciona únicamente como negación, es una afirmación deducible a partir del texto de Mariátegui llamado Nacionalismo e Internacionalismo (que problematiza el fascismo): "Como los relativistas ante la física de Galileo, los internacionalistas no contradicen toda la teoría nacionalista. Reconocen que corresponde a la realidad, pero sólo en primera aproximación. El nacionalismo aprehende una parte de la realidad; pero nada más que una parte. La realidad es mucho más amplia, menos finita. En una palabra, el nacionalismo es válido como afirmación, pero no como negación" (Mariátegui, 1970).
} 
Lucía Rey. José Carlos Mariátegui y el futurismo italiano: una perspectiva latinoamericana.

Darío, Rubén (1988). Marinetti y el futurismo. En: Osorio, Nelson. Manifiestos, proclamas y polémicas de la vanguardia literaria hispanoamericana. Caracas: Ayacucho. 3-7.

Fabris, Annateresa (2011). O futurismo como estética patológica: alguns aspectos de sua recepção no Brasil. En: Dossier thématique: Brésil, questions sur le modernisme. Artelogie (1), septiembre. Recuperado el 16 de noviembre de 2016 de http://cral.in2p3.fr/artelogie/spip.php?article67

(1990). A questão futurista no Brasil. En: Belluzo, Ana María, org. Modernidade: Vanguardas artísticas na América Latina. San Pablo: Memorial de América Latina / UNESP. 67-80.

Figueroa, Noelia (2012). Walter Benjamin y José Carlos Mariátegui: gestos para refundar una teoría crítica subalterna. Herramienta (51). Recuperado el 16 de noviembre de http://www.herramienta.com.ar/revista-herramienta-n-51/walter-benjamin-yjose-carlos-mariategui-gestos-para-refundar-una-teoria-cr

Gadamer, Hans Georg (1984). Verdad y Método. Fundamentos de una hermenéutica filosófica. España: Sígueme.

Galende, Federico (2009). Walter Benjamin y la destrucción. Santiago: Metales Pesados.

Gramsci, Antonio (1964). Carta a Trotski (8 de septiembre de 1922). En: Ferrata, Giansiro; Gallo, Niccolò. 2000 pagine di Gramsci, I. Milán: II Saggiatore. 366. Recuperado el 16 de noviembre de 2016 de http://www.gramsci.org.ar/1922-26/04-carta-trotzki.htm.

(1998). Socialismo y cultura. Para la reforma moral e intelectual. Madrid: Los Libros de la Catarata.

Gusdorf, Georges (1970). Mito y metafísica. Buenos Aires: Nova.

Jung, Carl. (1937). Tipos psicológicos. Santiago: Letras.

Lefebvre, Henri (1973). Más allá del estructuralismo. Buenos Aires: Península.

(1971). Contribución a la estética. Buenos Aires: La Pléyade.

Löwy, Michael (2012). Comunismo y religión: la mística revolucionaria de José Carlos Mariátegui. Herramienta (51).

Mariátegui, José Carlos (1970). El alma matinal. Lima: Amauta.

(1986). Peruanicemos el Perú. Lima: Amauta.

Marinetti, Filippo Tommaso (25 de marzo de 1912). Proa.org. Recuperado el 16 de noviembre de 2016, de http://www.proa.org/esp/exhibition-el-universo-futurista-manifiestos.php

Martín, Sylvia (2005). Futurismo. Madrid: Taschen.

Mazzeo, Miguel (2012). Apuntes sobre la hermenéutica mariateguiana. Herramienta (51). 
Saint-Point, Valentine de (2010). Manifiesto de la mujer futurista. Respuesta a F. T. Marinetti (25 de marzo de 1912). En: Belli, Gabriela, cur. Exhibición El universo futurista: manifiestos. Buenos Aires: Fundación Proa. Recuperado el 16 de noviembre de 2016 de http://www.proa.org/esp/exhibition-el-universo-futurista-manifiestos.php.

Saítta, S. (s.f.). Historiapolitica.com. Recuperado el 16 de noviembre de 2016, de http://historiapolitica.com/datos/biblioteca/visitas\%20culturales_saitta.pdf

Sartor, Mario (2012). El futurismo italiano y sus ecos latinoamericanos. En: Seminario Internacional de Conservação de Escultura Moderna. São Paulo: MAC USP. Recuperado el 16 de noviembre de 2016 de http://www.mac.usp.br/mac/conteudo/academico/publicacoes/anais/modernidade/pdfs/MARIO_ESP.pdf.

Schlegel, Friedrich (1994). Poesía y Filosofía. Madrid: Alianza.

Torres, Rodrigo, inv. resp. (1991). Aproximación a Pablo Garrido y a su obra desde sus archivos personales. Informe Fondecyt Regular 1910985 (inédito). Santiago: Fac. de Artes, U. de Chile. 